\title{
Chestnut High Forest Stands: Biometrical Study in the North of Portugal
}

L.F. Nunes, M.L. Monteiro and M.S. Patrício

Department of Forestry

Polytechnic Institute of Bragança, ESAB

Campus de Santa Apolónia

Apartado 172

5301-855 Bragança

Portugal

T. Alpuim

Department of Statistics and Operations Research

University of Lisbon

1749-016 Lisbon

Portugal

Keywords: Castanea sativa Mill., high forest, regression analysis, volume equations, height-diameter equations

\begin{abstract}
Growing sweet chestnut (Castanea sativa) in high forest stands is a lucrative investment. Wood with medium and large dimensions can attain interesting profitability levels. Furthermore, forest producers are interested of new on this species and decision criteria for the best management are needed for landowners. So, accuracy is very important when evaluating volume in standing trees. Based on regression theory, predicting equations of wood volume are developed as a function of tree variables easily measured (fast and cheap), such as diameter at breast height $(D B H)$ and tree total height $(h)$. Variable selection in volume equations was based on a stepwise modified procedure (linear models) and using generalized-F tests (nonlinear models). The resulting volume equation, with $D B H$ and $h$ as regressors, was confronted with the equation recommended by the Portuguese Forest Services. In order to evaluate wood volume at the lowest costs, the height to diameter relationship was also analyzed. Candidate regression equations were evaluated based on fitting statistics and validation statistics, complemented with the use of generalized-F tests. The biological behavior of the equations was also considered.
\end{abstract}

\section{INTRODUCTION}

Castanea sativa wood quality is well recognized among the most important broadleaved species (Monteiro et al., 1990). The distribution area of chestnut is increasing nowadays in Portugal and, over the last decade, many new high forest stands were established supported by the European Union (M.L. Monteiro, pers. commun., 2001). The main objective for these young plantations is to produce high quality wood. Logs with medium and large dimensions can attain interesting profitability levels $\left(125 € / \mathrm{m}^{3}\right.$ wood, referred to trees with $D B H$ higher than $30 \mathrm{~cm}$ ).

For chestnut high forest, there is a lack of decision criteria for adopting the best management. The accurate determination of wood volume is very important. Portuguese Forest Services usually use an official equation (Fortuna, 1969) based on data from forests located at the Estrela mountain (central Portugal). As a result of the generalized application of this official equation in Portuguese chestnut stands, there is evidence on the existence of revenue losses for some wood producers caused by the underestimation of volume and, consequently, wood monetary value (Monteiro et al., 1990).

Based on data obtained from three permanent research plots established in chestnut forested areas of northern Portugal, regression analysis was used to obtain volume equations as a function of variables easily measured in standing trees. An additional objective was modelling the height to diameter $(h-D B H)$ relationship in order to minimize costs of volume estimation. 


\section{MATERIAL AND METHODS}

\section{Sampling Sites and Data Collection}

In 1990, two permanent research plots were established in Castanea sativa high forest stands: one (0.05 ha) located in Bornes and the other ( $0.1 \mathrm{ha})$ located in Padrela. In 1992, two more permanent plots, both with an area of 0.05 ha were established in Marão (Fig. 1). Table 1 presents some characteristics of these plots. All trees from each plot were measured for $D B H$ and $h$. For volume determination, the Biterlich tele-relascope was used to obtain upper stem diameters and the corresponding heights. Tree volume was calculated by application of Smalian formula to logs. For the stump $(\mathrm{h} \leq 0.15 \mathrm{~m})$ and the tip (diameter $<7 \mathrm{~cm}$ ), the cylinder and the cone formulas, were applied respectively.

In 2000 , a $2^{\text {nd }}$ measurement was carried out re-evaluating $D B H$ and $h$ in all plots except in Padrela, were removal cutting already occurred.

\section{Volume Equations}

1. Variable Selection. Establishment of volume equations was based on data from the $1^{\text {st }}$ measurement. From total data, $2 / 3$ was used for fitting equations and $1 / 3$ used for crossvalidation. On both subsets, a balanced distribution of the trees by diameter classes was taken into account. For variable selection, linear and nonlinear equations were fitted in EXCEL using ordinary least squares (OLS).

The analysis of the simple correlation matrix for the volume predicting variables most found in forestry bibliography $\left(f d^{2} h, d^{2} f, f, d^{2} h, d^{2}, d, d h, h^{2}\right.$, and $\left.h\right)$, was the basis of the methodology used in linear equations (Table 2). Variable $h$ is defined as before, $d$ is the $D B H$ and variable $f$ represents the tree form and refers to the ratio $d_{5.30} / d$, where $d_{5.30}$ is the diameter over bark at $5.30 \mathrm{~m}$ high $(\mathrm{cm})$. This ratio was called Girard modified coefficient $(C g)$. For variable selection, a modified version of stepwise procedure was used where, at each step, a variable can enter in the model only if its multiple correlation coefficient with the variables already in the model is not higher than a value that was fixed in 0.9 (Nunes, 2001). Stepwise analysis as a useful tool for variable selection should be carefully used when collinearity exists among regressors, which may cause that the estimates of the regression coefficients are unstable and have large standard errors. (Afifi and Clark, 1996; Chatterjee et al., 2000; Maroco, 2003). The objective of our procedure was to avoid this type of problems. When there are two variables in the model $\left(\mathrm{X}_{1}\right.$ and $\left.\mathrm{X}_{2}\right)$, all other variables with multiple correlation with $\left(\mathrm{X}_{1}, \mathrm{X}_{2}\right)$ greater than 0.9 were not allowed to enter.

Nonlinear equations were first fitted in linear form using logarithmic transformation. Then, all regression theory for linear models still applies. For variable selection we used generalized-F tests, (Ryan, 1997), fitting first the more general model (full model) and testing against the subset of reduced models (Nunes, 2001).

At the final, the best linear and nonlinear equations were compared based on fitting statistics and validation statistics (Fig. 2). Scatterplots of observed against predicted volume were also observed. Normal Q-Q plots showed no violation to normality of residuals.

2. Equations Comparison among Sampling Sites. Best final volume equations were reestimated using total data with exclusion of inconsistent observations and compared among sampling sites using generalized F-tests (Sen and Srivastava, 1997).

\section{Height-Diameter Equations}

The data from the $1^{\text {st }}$ and $2^{\text {nd }}$ measurements was used for modeling the $h-D B H$ relationship. The shape of the height curve changes with management practices, age and site quality (Loetsch et al., 1973). Because of that, equations were established by sampling sites, using in each case, $2 / 3$ of available data for fitting equations and $1 / 3$ for cross-validation.

The candidate equations were selected from the bibliography. Linear equations were fitted by OLS and by nonlinear least squares (NLS) using Gauss-Newton algorithm 
in STATISTICA. Comparison of the equation's performance was mainly based on fitting and validation statistics mentioned before (Fig. 2). The significance of the regression coefficients was analyzed based on T-tests. Biological behavior of the models was also verified. Best final equations were compared but now, for each site, among sampling dates.

\section{RESULTS}

For each site, after evaluating performance, resulting $h-D B H$ best equations fitted to total data, are presented:

Padrela: $h=0.05368706 d^{3.33909309-0.45454766 \text { Lnd }}$

$$
\begin{aligned}
& \left(R^{2}=0.65 ; S=1.7 ; n=65\right) \\
& \left(R^{2}=0.71 ; S=1.5 ; n=145\right) \\
& \left(R^{2}=0.48 ; S=5.2 ; n=104\right)
\end{aligned}
$$

Bornes: $h=-5.02725666+8.14601227$ Lnd

Marão: $h=e^{4.02779067-30.89711940(1 / d)}$

$h$ - tree total height $(\mathrm{m})$

$d-\mathrm{DBH}(\mathrm{cm})$

$\mathrm{R}^{2}$ - coefficient of determination

$\mathrm{S}$ - standard deviation of estimates $(\mathrm{m})$

$\mathrm{n}$ - number of observations

As the result of the applied methodology for variable selection and model comparison, best final volume equations follow ( $\mathbf{a}$ - Bornes and Padrela, $\mathbf{b}$ - Marão):

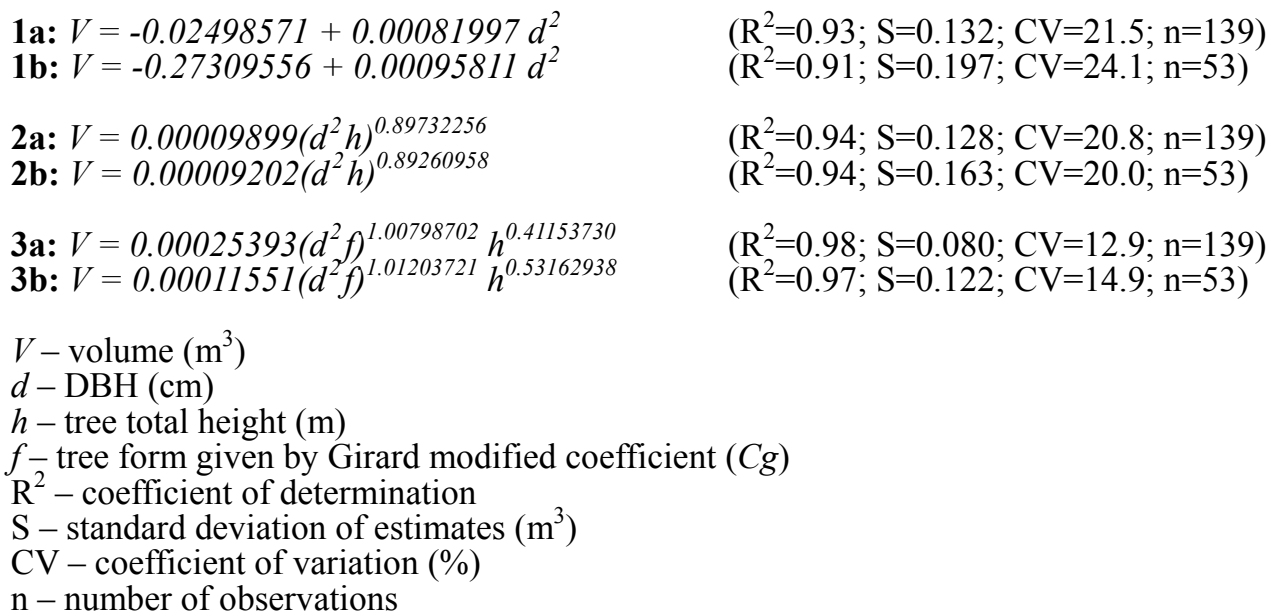

\section{DISCUSSION}

\section{Height-Diameter Relationship}

Attaining values of standard deviation of estimates (S), best final $h-D B H$ equations give satisfactory results for Padrela and Bornes, estimating height with precisions of 1.7 and 1.5 metres respectively. Corresponding coefficients of variation (CV) are $7.1 \%$ and $7.6 \%$. In opposite, equation for Marão only explains $48 \%$ of total height variation, presenting high values of $\mathrm{S}$ and $\mathrm{CV}$. Site quality seems to be different concerning the two plots established in Marão and, if the selected equation is fitted separately for these plots, values for $\mathrm{R}^{2}$ are still low but $\mathrm{S}$ values are similar to those for Bornes and Padrela.

Comparisons to analyse evolution of $h-D B H$ relationship between measurements, was only possible in Bornes and Marão. The chestnut stand in Bornes maintains, since 
initial plantation, a high level of growing stock. Competition increased and growth potential is becoming limited. We can see that 10 years after the $1^{\text {st }}$ measurement, the slope of the height curve is almost the same. For Marão and considering plot 1 , coefficients of the equation do not differ significantly between the $1^{\text {st }}$ and the $2^{\text {nd }}$ measurement. In opposite, significant difference exists in the slop for plot 2. This plot shows lower growth pattern than plot 1 and the plots from Bornes and Padrela.

\section{Volume}

For volume equations as a function of $D B H$ (1a and $1 \mathrm{~b})$, the coefficient of variation (CV) was $26.7 \%$, being slightly high. When variable $h$ is added to the model, $\mathrm{CV}$ decreases by $4 \%$-units. Moreover, when variable $f$ enters in the model, $\mathrm{CV}$ decreases by $10.1 \%$-units in relation to the equation with only $D B H$ as regressor and by $6.5 \%$-units in relation to the equation with regressors $D B H$ and $h$. Inclusion of variable tree form in the volume prediction model, led to substantial improvement in precision. Results comparing each type of equation among sampling sites, showed that there was no significant difference in regression coefficients values between Bornes and Padrela but, on the contrary, significant difference exists either between Bornes and Marão and Padrela and Marão.

Based on a 892 trees sample from a high forest chestnut stand located in Estrela Mountain (central Portugal), volume equations were established (Fortuna, 1969), using either Huber and Smalian formulas for volume evaluation. These equations have been recommended by the Forest Services. Equation resulting from Huber formula application (official) is:

$V=-0.00246+0.0001684 g+0.0000303 g h\left(\mathrm{~S}=0.019 \mathrm{~m}^{3} ; \mathrm{CV}=8.93 \%\right)$.

where $g$ is the basal area $\left(\mathrm{cm}^{2}\right), V$ is the volume $\left(\mathrm{m}^{3}\right)$ and $h$ is the total height $(\mathrm{m})$.

Resulting equations 2a (Bornes and Padrela) and 2b (Marão) were compared with the Forest Services official equation (FS) (Fig. 3). It can be seen that the FS equation clearly underestimates volume when applied in Bornes and Padrela, mainly for volume above $0.5 \mathrm{~m}^{3}$. In Marão, both equations ( $2 \mathrm{~b}$ and FS) present similar performance for the entire interval of observed volumes.

\section{CONCLUSIONS}

Usually $D B H$ and $h$ explain almost total variability of variable volume. Nevertheless, in the particular case of this study, the tree form $(f)$ is shown to be an important regressor for predicting chestnut wood volume, causing considerable reduction in standard deviation of estimates (S) values. However, tree form is a difficult and time wasting variable to measure. So, to evaluate as accurate as possible the volume of chestnut high forest stands from Bornes, Padrela and Marão, the following equations are proposed:

$$
\begin{aligned}
& V=0.00009899\left(d^{2} h\right)^{0.89732256} \text { (Bornes and Padrela) } \\
& V=0.00009202\left(d^{2} h\right)^{0.89260958} \text { (Marão) }
\end{aligned}
$$

To estimate tree total height in Padrela and Bornes it is acceptable to use the equations, respectively:

$h=0.05368706 d^{3.33909309-0.45454766 \text { Lnd }}$
$h=-5.02725666+8.14601227$ Lnd

In order to reduce time and costs in volume predictions, improvement in modelling the height-diameter relationship should be considered, mainly in Marão. 


\section{Literature Cited}

Afifi, A.A. and Clark, V. 1996. Computer-Aided Multivariate Analysis. $3^{\text {rd }}$ Ed., Chapman \& Hall, London.

Alves, A.M. 1988. Técnicas de Produção Florestal. Instituto Nacional de Investigação Científica. $2^{\text {a }}$ Edição, Lisboa.

Chatterjee, S., Hadi, A.S. and Price, B. 2000. Regression Analysis by Example. $3^{\text {rd }}$ Ed., John Wiley, New York.

Fortuna, E.R.M. 1969. Tabelas de volume para o castanheiro bravo. Secretaria de Estado da Agricultura. Direcção Geral dos Serviços Florestais e Aquícolas, Série Estudos e Informação 245, Lisboa.

Loetsch, F., Zöhrer, F. and Haller, K.E. 1973. Forest Inventory, Vol. II. Verlagsgesellschaft, Münich.

Maroco, J. 2003. Análise Estatística com utilização do SPSS. Edições Sílabo, Lisboa.

Monteiro, M.L., Sales Luís, J.F. and Oliveira, A.C. 1990. Crescimento e produção de povoamentos de Castanea sativa Miller em alto fuste: Primeiros resultados. Actas do II Congresso Florestal Nacional, Faculdade de Economia, Porto. p.360-367.

Nunes, L.F. 2001. Estudo biométrico com vista à elaboração de tabelas de volume para o castanheiro. Tese de Mestrado, FCUL, Lisboa.

Ryan, T.P. 1997. Modern Regression Analysis. Theory, Methods and Applications. Springer Verlag, New York.

Sen, A. and Srivastava, M. 1997. Regression Analysis. Theory, Methods and Applications. $2^{\text {nd }}$ Ed., Springer Texts in Statistics, Springer Verlag, New York.

$\underline{\text { Tables }}$

Table 1. Principal characteristics of research sites.

\begin{tabular}{lcccccc}
\hline Site & $\begin{array}{c}\text { Latitude }(\mathrm{N}) \\
\text { Longitude }(\mathrm{W})\end{array}$ & $\begin{array}{c}\text { Altitude } \\
(\mathrm{m})\end{array}$ & Exposure & $\begin{array}{c}\text { Slope } \\
\left({ }^{\circ}\right)\end{array}$ & Soil type & Ecological zone $^{\text {a }}$ \\
\hline Bornes & $\begin{array}{l}4^{\circ} 29^{\prime} 37^{\prime \prime} \mathrm{N} \\
\text { Marão }\end{array}$ & 780 & North & 18 & Schist & $\begin{array}{c}\text { Montano } \\
\text { 6 } 55^{\prime} 12^{\prime \prime} \mathrm{W}\end{array}$ \\
$\begin{array}{c}41^{\circ} 14^{\prime} 24^{\prime \prime} \mathrm{N} \\
7^{\circ} 55^{\prime} 38^{\prime \prime} \mathrm{W}\end{array}$ & 940 & South & 7 & Granite & $\begin{array}{c}\text { Montano } \\
\text { A.SA }\end{array}$ \\
& $\begin{array}{c}41^{\circ} 30^{\prime} 34^{\prime \prime} \mathrm{N} \\
\text { Padrela }\end{array}$ & 830 & North & 29 & Granite & $\begin{array}{c}\text { Montano } \\
\text { SA }\end{array}$ \\
\hline
\end{tabular}

${ }^{\mathrm{a}}$ Alves (1988) 
Table 2. Simple correlation matrix for regressors with interest in volume prediction.

\begin{tabular}{lcccccccccc}
\hline & $f$ & $f d^{2} h$ & $d^{2} f$ & $d^{2} h$ & $d^{2}$ & $d$ & $d h$ & $h^{2}$ & $h$ & $V$ \\
\hline$f$ & $\mathbf{1}$ & & & & & & & & & \\
$f d^{2} h$ & 0.3695 & $\mathbf{1}$ & & & & & & & \\
$d^{2} f$ & 0.3661 & 0.9805 & $\mathbf{1}$ & & & & & & \\
$d^{2} h$ & 0.2553 & 0.9862 & 0.9667 & $\mathbf{1}$ & & & & & \\
$d^{2}$ & 0.2145 & 0.9589 & 0.9815 & 0.9759 & $\mathbf{1}$ & & & & & \\
$d$ & 0.2527 & 0.9296 & 0.9644 & 0.9440 & 0.9812 & $\mathbf{1}$ & & & & \\
$d h$ & 0.3405 & 0.9705 & 0.9465 & 0.9783 & 0.9461 & 0.9466 & $\mathbf{1}$ & & & \\
$h^{2}$ & 0.4467 & 0.8235 & 0.7421 & 0.8197 & 0.7187 & 0.7367 & 0.9022 & $\mathbf{1}$ & & \\
$h$ & 0.4987 & 0.7966 & 0.7261 & 0.7884 & 0.6961 & 0.7219 & 0.8828 & 0.9896 & $\mathbf{1}$ & \\
$V$ & 0.3747 & 0.9716 & 0.9747 & 0.9537 & 0.9482 & 0.9242 & 0.9370 & 0.7656 & 0.7472 & $\mathbf{1}$ \\
\hline
\end{tabular}

$V$-volume $\left(\mathrm{m}^{3}\right)$

$d-\mathrm{DBH}(\mathrm{cm})$

$h$ - tree total height $(\mathrm{m})$

$f$ - tree form given by Girard modified coefficient $(\mathrm{Cg})$

$C g$ - Girard modified coefficient $\left(d_{5,30} / d\right)$ where

$d_{5.30}$ - diameter over bark at $5.30 \mathrm{~m}$ high $(\mathrm{cm})$

(Correlation formula):

$r_{x y}=\frac{\sum_{i=1}^{n}\left(x_{i}-\bar{x}\right)\left(y_{i}-\bar{y}\right)}{\sqrt{\sum_{i=1}^{n}\left(x_{i}-\bar{x}\right)^{2} \sum_{i=1}^{n}\left(y_{i}-\bar{y}\right)^{2}}}$

\section{Figures}

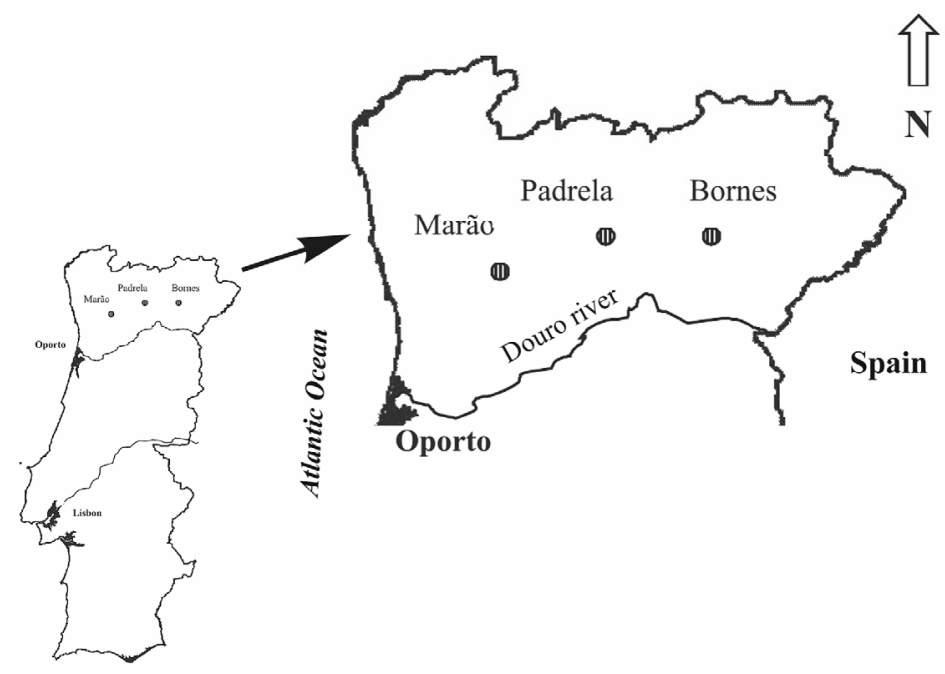

Fig. 1. Location of the research plots. 


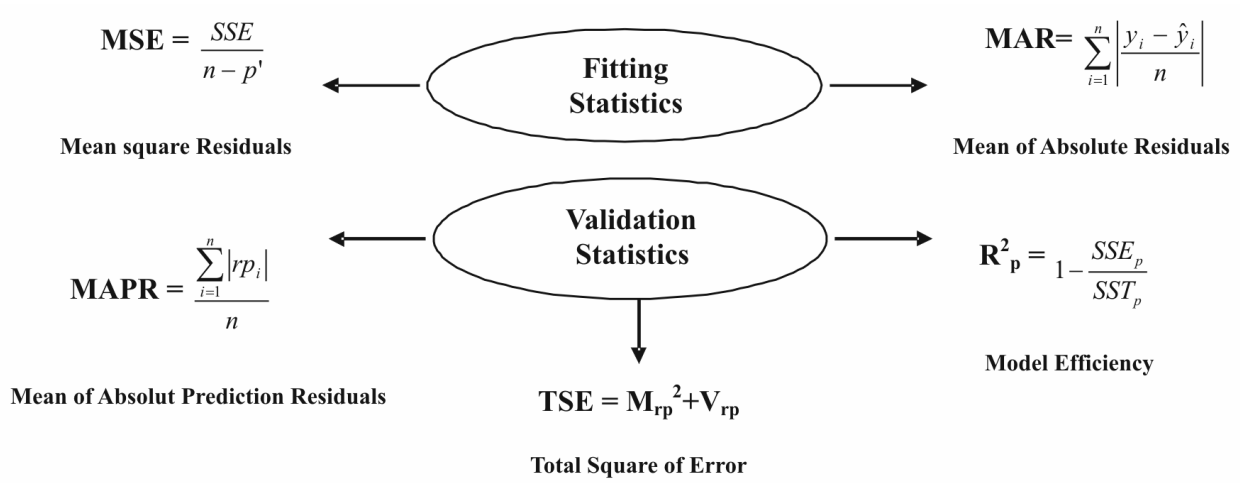

Fig. 2. Statistics used to compare equation's performance. SSE: residual sum of squares, $r p_{i}$ prediction residual for observation, $\mathrm{M}_{\mathrm{rp}}{ }^{2}$ : squared mean of prediction residuals, $\mathrm{V}_{\mathrm{rp}}$ : variance of prediction residuals, $\mathrm{SSE}_{\mathrm{p}}$ : residual sum of squares for validation dataset, $\mathrm{SST}_{\mathrm{p}}$ : total sum of squares for validation dataset.

\section{(Bornes and Padrela)}

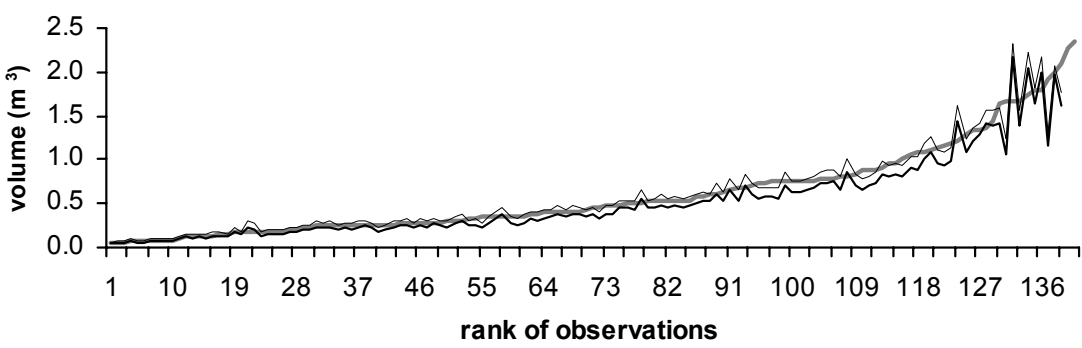

- observed - $2 a \quad$ FS

(Marão)

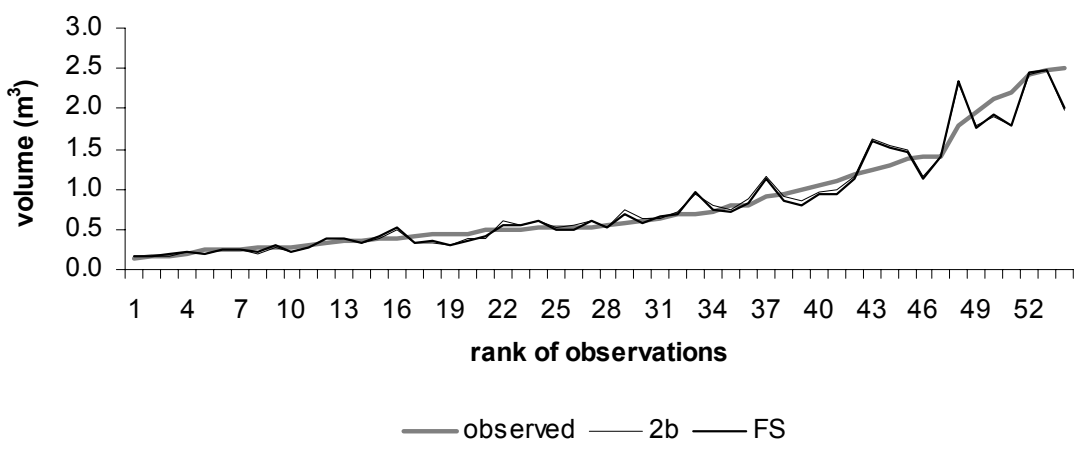

Fig. 3. Equations $2 \mathrm{a}$ and $2 \mathrm{~b}$ compared with Forest Services official equation (FS). 
